ISSN 0258-7122

Bangladesh J. Agril. Res. 39(1): 67-77, March 2014

\title{
EFFECTS OF FOLIAR APPLICATION OF POTASSIUM ORTHOPHOSPHATE ON GRAIN YIELD AND KERNEL QUALITY OF WHEAT (Triticum aestivum) UNDER TERMINAL HEAT STRESS
}

\author{
M. ATAUR RAHMAN ${ }^{1}$, M. M. RAHMAN ${ }^{1}$, M. M. HASAN ${ }^{1}$ \\ FARIDA BEGUM ${ }^{2}$ AND M. A. Z. SARKER ${ }^{3}$
}

\begin{abstract}
A field experiment was conducted at Bangladesh Agricultural Research Institute (BARI) farm, Gazipur to evaluate the effect of foliar application of potassium orthophosphate on grain yield and kernel quality of wheat under the terminal heat stress imposed by late sowing for two consecutive years (2008-09 and 2009-10). Five combinations of foliar applications of potassium orthophosphate and Tilt were tested on three wheat varieties, namely Kanchan, Shatabdi, and Prodip. The result indicated that foliar application of potassium orthophosphate was effective in increasing SPAD value (Measure of leaf chlorophyll content) and leaf area of all the wheat varieties, whereas Tilt application was effective only in Kanchan. The grain size of wheat in terms of 1000-grain weight was improved and thereby contributed to grain yield. Also the foliar application of potassium orthophosphate decreased the number of immature, smaller and deformed kernel, and thus improved the kernel quality. Two foliar sprays of $0.1 \%$ potassium orthophosphate solution at 70 DAS (Days after sowing) and 80 DAS performed better results than other applications. There were varietal differences in response to foliar treatments and the variety Prodip and Shatabdi were more responsive to potassium orthophosphate compared to Kanchan. Potassium orthophosphate could be suggested to improve grain yield and kernel quality of wheat under terminal heat stress condition.
\end{abstract}

Keyword: Osmotic solute, heat stress, wheat genotype, kernel quality, SPAD value

\section{Introduction}

Intensive farming of cereal crops in order to produce more food often compels the late sowing of wheat under the rice based cropping systems in Bangladesh. Late-sown wheat is usually exposed to high temperature during flowering to grain-filling stages of the crop due to short spell of winter in Bangladesh (Ahmed and Meisner, 1994). High temperature enhances leaf senescence and reduces green area duration that affects the production of photosynthates and thereby results in shrivels and smaller grains (Rahman et al., 2005). The yield reduction of wheat under higher temperature is associated with a less number of

\footnotetext{
${ }^{1}$ Regional Wheat Research Centre, Bangladesh Agricultural Research Institute (BARI), Gazipur 1701, ${ }^{2}$ Crop Physiology Division, BARI, Gazipur 1701, ${ }^{3}$ Wheat Research Centre, BARI, Nashipur, Dinajpur, Bangladesh.
} 
grains/spike and smaller grain size (Gibson and Paulsen, 1999). Also the loss of green area due to fungal disease, especially BpLB (Bipolaris leaf blight) increases with the increase in temperature (Iftikhar et al., 2010). All these fact ultimately contribute to substantial yield loss of wheat under the terminal heat stress conditions. Yield reduction due to high temperature varies with variation of temperatures, duration of exposure, and plant growth stages (Gibson and Paulson, 1999). Attempts to maintain the plant physiological regulation by agronomic manipulation could be useful to improve grain production under the terminal heat stress condition. Foliar application of osmotic solutes (potassium orthophosphate) could be an option to increase the thermal tolerance through osmotic adjustment in wheat leaf. Foliar application of potassium orthophosphate may delay high temperature or drought induced leaf senescence and thus improve grain yield of wheat (Benbella and Paulsen, 1998). Application of potassium orthophosphate results higher $\mathrm{K}^{+}$content, increases soluble sugar and proline content in leaf (Hongbo et al., 2005) and thereby might contribute to heat tolerance. Thus foliar application of potassium orthophosphate may have potentials in maintaining longer green area duration with higher leaf chlorophyll that ultimately contribute to yield and quality of wheat grain. However, crop response to osmotic solute may vary with variation of genotypes that need to be investigated to improve wheat yield under high temperature stress. Therefore, the experiment was conducted to evaluate the effectiveness of osmotic solute in improving grain yield and quality of wheat under high temperature.

\section{Materials and Method}

The field experiment was conducted at the central farm of Bangladesh Agricultural Research Institute (BARI), Gazipur (23⒌ $59^{\prime} \mathrm{N}, 90^{\circ} 24^{\prime} \mathrm{E}$, and $12 \mathrm{~m}$ above sea level) for two consecutive years of 2008-09 and 2009-10. The soil of the experimental field belongs to AEZ 28, which is characterized by flood free highland, fine in texture (Silty clay loam), poor in organic matter $(1.1 \%)$, and $\mathrm{N}$ $(0.07 \%)$ contents. The entire wheat growing period in 2008-09 was severely dry with no precipitation and also the relative humidity was lower in this season compared to 2009-10 (Figs. 1 and 2). In 2009-10 cropping season, the crop received $17 \mathrm{~mm}$ rainfall during grain filling period that was adjusted during third irrigation. The daily minimum and maximum temperatures throughout the growing season were measured and presented in Fig. 1 and 2 as weekly mean. During the grain filling to maturity (February to March), the weekly average maximum temperature ranged from $27.5^{\circ} \mathrm{C}$ to $34.0^{\circ} \mathrm{C}$ in $2008-09$ and from $28.0^{\circ} \mathrm{C}$ to $35.5^{\circ} \mathrm{C}$ in $2009-10$ which indicated that the crop was exposed to terminal heat stress in both the years. 


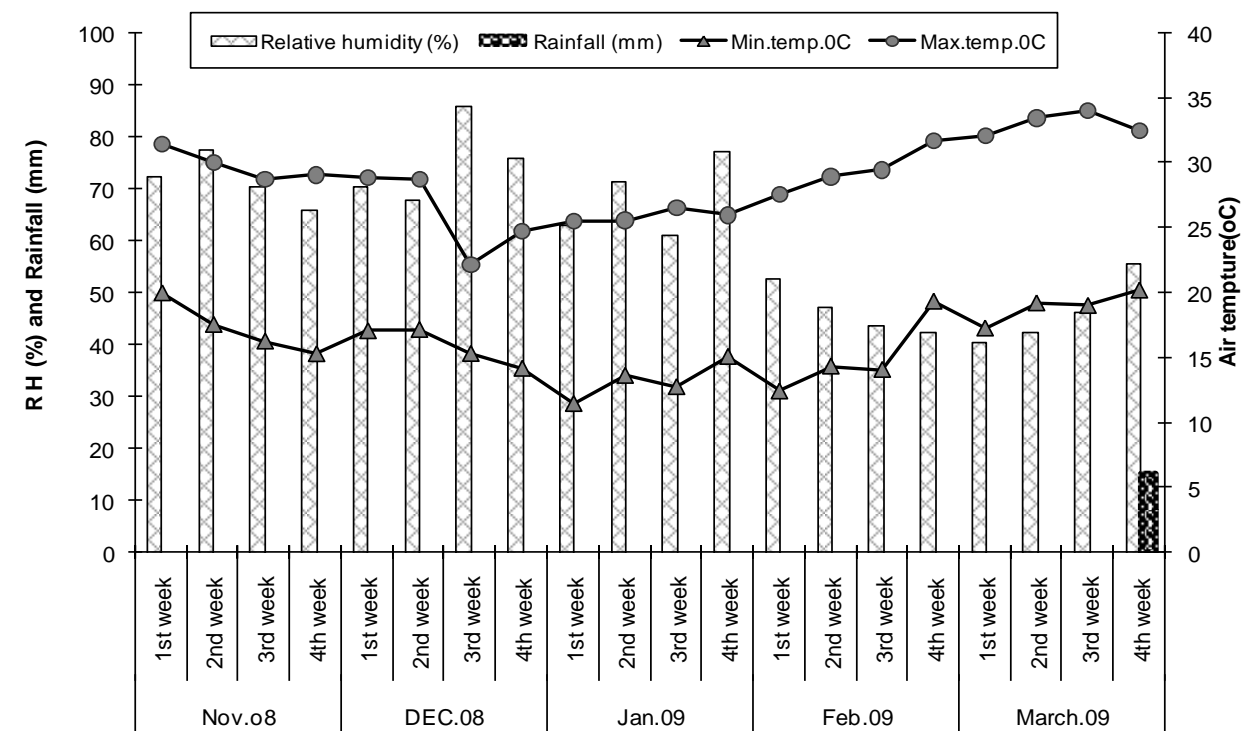

Fig. 1. Weekly average maximum and minimum air temperature, rainfall and relative humidity $(\mathrm{RH})$ during the cropping period of 2008-09.

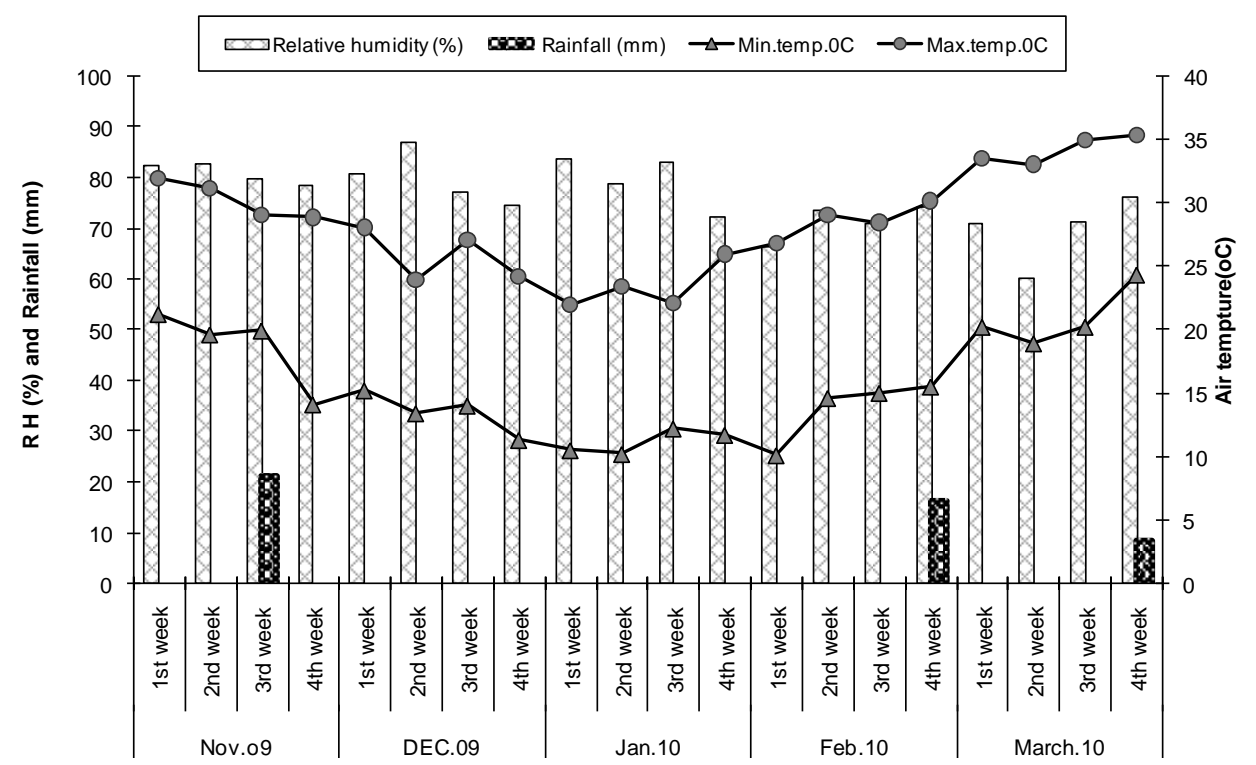

Fig. 2. Weekly average maximum and minimum air temperature, rainfall and relative humidity (RH) during the cropping period of 2009-10. 


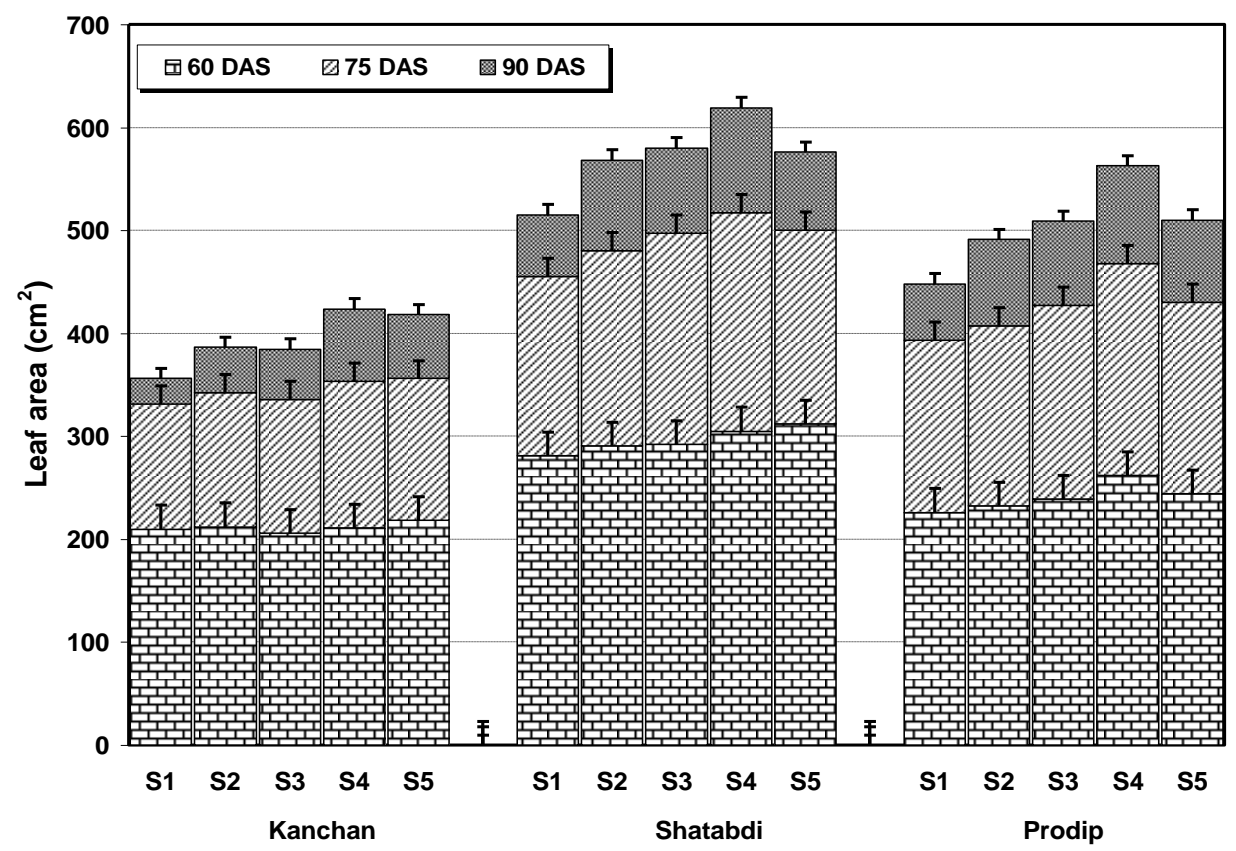

Fig. 3. Effect of osmotic solute on leaf area of 3 wheat cultivars at 3 different growth stages (DAS-Days after sowing, ; $S_{1}=$ Control $S_{2}=$ Foliar spray of $\mathrm{KH}_{2} \mathrm{PO}_{4}$ at $70 \mathrm{DAS}, \mathrm{S}_{3}=$ Foliar spray of $\mathrm{KH}_{2} \mathrm{PO}_{4}$ at $80 \mathrm{DAS}, \mathrm{S}_{4}=$ Foliar spray of $\mathrm{KH}_{2} \mathrm{PO}_{4}$ at 70 and $80 \mathrm{DAS}$, and $S_{5}=$ Foliar spray of Tilt $250 \mathrm{EC}$ at 70 and $80 \mathrm{DAS}$ )

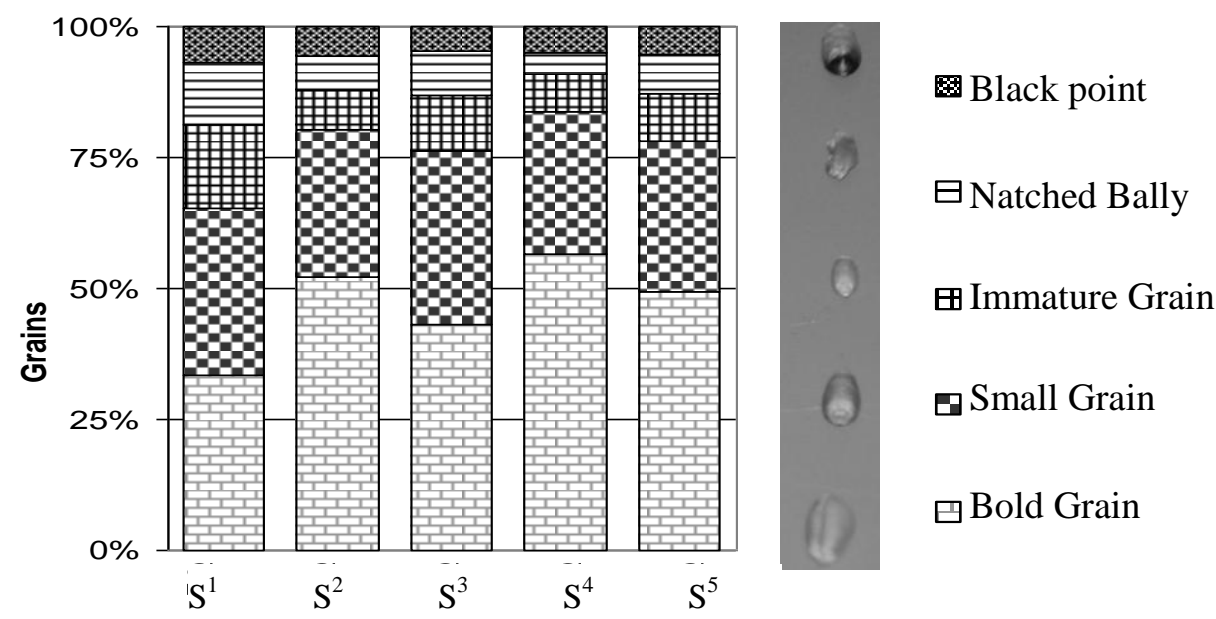

Fig. 4. Pictorial view of Kernel size distribution and quality $(\%)$ of wheat under different foliar treatments; $S_{1}=$ Control $S_{2}=$ Foliar spray of $\mathrm{KH}_{2} \mathrm{PO}_{4}$ at 70 DAS, $\mathrm{S}_{3}=$ Foliar spray of $\mathrm{KH}_{2} \mathrm{PO}_{4}$ at 80 DAS, $\mathrm{S}_{4}=$ Foliar spray of $\mathrm{KH}_{2} \mathrm{PO}_{4}$ at 70 and 80 DAS, and $S_{5}=$ Foliar spray of Tilt 250 EC at 70 and 80 DAS). 
The experiment was executed in split plot design where three wheat varieties, namely Kanchan $\left(\mathrm{V}_{1}\right)$, Shatabdi $\left(\mathrm{V}_{2}\right)$, and Prodip $\left(\mathrm{V}_{3}\right)$ were distributed to the main plots and five foliar treatments were imposed to the subplots. Foliar treatments were $S_{1}=$ Control i.e., spraying of water at 70 DAS (Days after sowing), $\mathrm{S}_{2}=$ Foliar spray of potassium orthophosphate $\left(\mathrm{KH}_{2} \mathrm{PO}_{4}\right)$ solution @ $0.1 \%$ at 70 DAS, $\mathrm{S}_{3}=$ Foliar spray of $\mathrm{KH}_{2} \mathrm{PO}_{4}$ solution @ $0.1 \%$ at $80 \mathrm{DAS}, \mathrm{S}_{4}=$ Two foliar sprays of $\mathrm{KH}_{2} \mathrm{PO}_{4}$ solution @ $0.1 \%$ at 70 and $80 \mathrm{DAS}$, and $\mathrm{S}_{5}=$ Two sprays of Tilt 250 Ec @ $0.05 \%$ at 70 and 80 DAS. Seeds were sown continuously in $20 \mathrm{~cm}$ spaced line at the rate of $120 \mathrm{~kg} / \mathrm{ha}$ on 17 December for 2008-09 and 18 December for 2009-10 experimental seasons. Fertilizers of N, P, K, and S at the rate of $100,38,50$, and $20 \mathrm{~kg} / \mathrm{ha}$, respectively, were applied as urea, triple super phosphate, muriate of potash, and gypsum, respectively. All fertilizers including two-third urea were uniformly applied in the field during final land preparation. The rest of urea was top dressed at CRI (Crown root initiation) stage after the first irrigation. The crop was irrigated uniformly thrice at 20,45, and 65 DAS by applying same amount of water in each sub-plot. Weeds were controlled once at 35 DAS manually by hand weeding. Leaf chlorophyll was measured at 75 and 90 DAS by using SPAD meter (MINOLTA 502). To ensure accuracy of the result, an average of 10 measurements from the same position of 10 flag leaves were considered as the mean value for each plot. At the same time, destructive samplings of those 10 plants were made to measure leaf area using an automatic leaf area meter (Model: AAM-8, Hayashi Denko, Tokyo). During maturity, 10 randomly selected plants were collected from each plot and were threshed separately to study grain quality. Grain quality of wheat in respect kernel size distribution, notched bally kernel, and black pointed kernel were estimated as a percent of total number of kernels. Also the mature crops were harvested from the central areas $(3 \mathrm{~m} \times 2 \mathrm{~m})$ of each sub-plot and after threshing the grains were dried in the atmosphere. Then moisture content of each sample was measured and grain yield was converted to $\mathrm{t} / \mathrm{ha}$ at $10 \%$ moisture to compare the treatment effects. All the data were statistically analyzed and the mean value was tested by the least significant difference (LSD) at 5\% level of significance.

\section{Results and Discussion}

\section{Leaf area and SPAD values}

Leaf area (LA) of wheat largely depends on the diversity of genotypes, plant growth stages, and plant exposure to abiotic stress like high temperature. During heading at 60 DAS, LA was the maximum in Shatabdi, whereas Kanchan and Prodip resulted in statistically similar LA. Different levels of foliar treatments 
had the similar non-significant effect on LA measured at 60 DAS for all the wheat varieties as the foliar treatments were not imposed until that stage. Thereafter, at 75 and $90 \mathrm{DAS}$, the trends changed and the plant response to foliar treatments became visible (Fig. 3). Leaf senescence enhanced by higher temperature caused reduction in green leaf area and thus LA at later stage (90 DAS) drastically decreased and the trend was common for all the varieties. However, there were differences in LA in response to foliar treatments. Particularly, the foliar treatment $\mathrm{S}_{4}$ resulted in higher LA at 90 DAS for all the varieties indicating that foliar application of potassium orthophosphate at 70 and 80 DAS reduced the high temperature induced leaf senescence. The maximum SPAD value was also recorded from the same treatment (Table 1). Larger LA with higher SPAD values at the later stages of crop growth might contribute to higher photosynthesis that ultimately contributed to higher grain yield. Genotypic difference in green leaf area duration in response to heat stress is also reported by other researchers (Stone and Nicolas, 1998; Fisher et al., 1998; Rahman et al., 2009). High temperature induced leaf senescence largely depends on membrane thermo-stability which varied with varietal tolerance. The specific role of potassium orthophosphate on membrane thermo-stability is not clear but its role as osmotic solute might contribute to stomatal adjustment and functioning and thus reduced the high temperature induce leaf senescence. All these fact ultimately resulted in comparatively high SPAD value and LA of wheat for $\mathrm{S}_{4}$ treatment. Due to the interaction of variety and foliar treatment, the combination of $\mathrm{V}_{2} \mathrm{~S}_{4}$ and $\mathrm{V}_{3} \mathrm{~S}_{4}$ performed high leaf SPAD values measured at 75 and 90 DAS. Also the maximum LA was produced from the $\mathrm{V}_{2} \mathrm{~S}_{4}$ and $\mathrm{V}_{3} \mathrm{~S}_{4}$ treatment combinations.

\section{Grain yield and yield components}

Spikes $/ \mathrm{m}^{2}$ and grains/spike, the two major yield components of wheat significantly varied due to varietal differences, but not for the foliar treatments or the interactions of variety and foliar treatments. The grain yield and 1000-grain weight were significantly influenced by the variety, foliar treatment, and their interaction (Table 1). The effect of variety on grain yield and yield components including leaf SPAD values at different dates were remarkable, Prodip being found dominating in all cases followed by Shatabdi and Kanchan. Under the higher temperature as induced by late sowing, leaf senescence occurred faster in Kanchan, thus the variety appeared to attain physiological maturity earlier compared to Prodip and Shatabdi. Green leaf area duration and leaf senescence at heat stress largely depends on membrane thermo-stability that might have been influenced by the interaction of genotypes and foliar treatments. In tolerant 
Table 1. Yield components and leaf traits of wheat as influenced by genotype, foliar treatments and their interactions.

\begin{tabular}{|c|c|c|c|c|c|c|c|}
\hline Treatment & $\begin{array}{c}\text { Spikes/ } \\
\mathrm{m}^{2}\end{array}$ & $\begin{array}{c}\text { Grains/ } \\
\text { spike }\end{array}$ & $\begin{array}{c}\text { 1000-grain } \\
\text { wt (g) }\end{array}$ & \multicolumn{2}{|c|}{ SPAD reading } & $\begin{array}{l}\text { Days to } \\
\text { maturity }\end{array}$ & $\begin{array}{c}\text { Grain yield } \\
(\mathrm{t} / \mathrm{ha})\end{array}$ \\
\hline \multicolumn{8}{|l|}{ A. Variety } \\
\hline Shatabdi & 310.3 & 40.1 & 45.4 & 41.0 & 33.2 & 108.4 & 3.90 \\
\hline Prodip & 315.6 & 40.9 & 47.0 & 40.9 & 37.6 & 109.5 & 4.19 \\
\hline $\mathrm{S}_{1}$ & 307.2 & 37.8 & 43.8 & 34.8 & 23.9 & 104.8 & 3.46 \\
\hline $\mathrm{S}_{2}$ & 317.8 & 39.5 & 45.6 & 39.1 & 32.3 & 108.3 & 3.84 \\
\hline $\mathrm{S}_{3}$ & 306.0 & 39.8 & 45.2 & 39.3 & 31.7 & 107.6 & 3.86 \\
\hline $\mathrm{S}_{4}$ & 313.1 & 41.7 & 48.0 & 42.5 & 40.9 & 110.5 & 4.23 \\
\hline $\mathrm{S}_{5}$ & 309.4 & 41.4 & 46.8 & 40.7 & 38.1 & 109.7 & 4.07 \\
\hline \multicolumn{8}{|l|}{ C. Interactions } \\
\hline $\mathrm{V}_{1} \mathrm{~S}_{3}$ & 294.5 & 40.1 & 44.4 & 32.2 & 23.2 & 105.0 & 3.35 \\
\hline $\mathrm{V}_{1} \mathrm{~S}_{4}$ & 305.3 & 40.9 & 45.8 & 36.5 & 33.5 & 107.6 & 3.70 \\
\hline $\mathrm{V}_{1} \mathrm{~S}_{5}$ & 302.4 & 41.2 & 46.6 & 38.9 & 37.3 & 109.7 & 3.89 \\
\hline $\mathrm{V}_{2} \mathrm{~S}_{1}$ & 307.3 & 38.6 & 43.8 & 37.1 & 28.2 & 106.3 & 3.69 \\
\hline $\mathrm{V}_{2} \mathrm{~S}_{2}$ & 318.7 & 41.3 & 45.4 & 42.3 & 33.2 & 109.7 & 3.91 \\
\hline $\mathrm{V}_{2} \mathrm{~S}_{3}$ & 313.8 & 38.3 & 45.1 & 44.5 & 33.8 & 109.0 & 4.11 \\
\hline
\end{tabular}


Table 1. Cont'd.

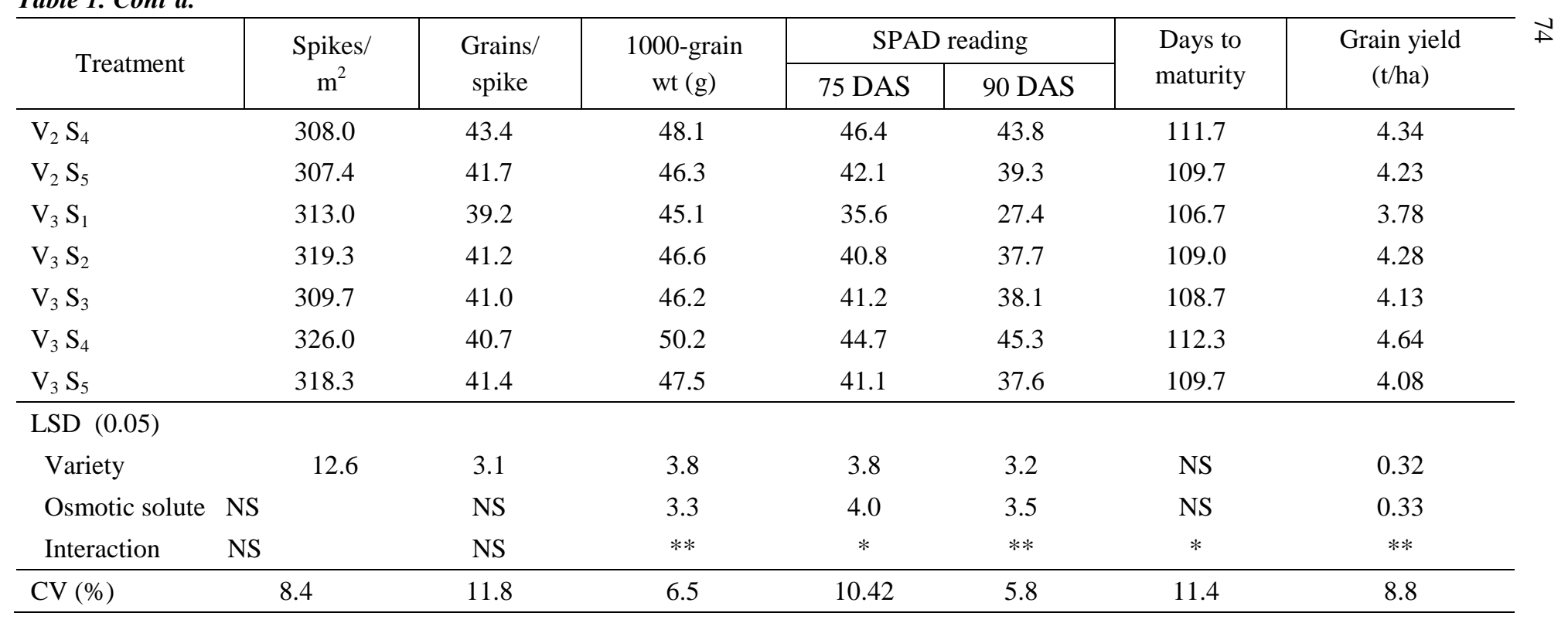

$\mathrm{V}_{1}$-Kanchan, $\mathrm{V}_{2}$-Shatabdi and $\mathrm{V}_{3}$-Prodip; $\mathrm{S}_{1}=$ Control $\mathrm{S}_{2}=$ Foliar spray of $\mathrm{KH}_{2} \mathrm{PO}_{4}$ at 70 DAS, $\mathrm{S}_{3}=$ Foliar spray of $\mathrm{KH}_{2} \mathrm{PO}_{4}$ at $80 \mathrm{DAS}$,

$\mathrm{S}_{4}=$ Foliar spray of $\mathrm{KH}_{2} \mathrm{PO}_{4}$ at 70 and $80 \mathrm{DAS}$, and $\mathrm{S}_{5}=$ Foliar spray of Tilt $250 \mathrm{EC}$ at 70 and $80 \mathrm{DAS}$. 
cultivars, leaf senescence is reported to occur after significant grain growth whereas in sensitive cultivars, leaf senescence occurs before substantial grain growth. High temperature induced forced maturation caused reduction in grain growth duration (Rahman et al., 2005) that finally resulted in lower 1000-grain weight and grain yield. Though spikes $/ \mathrm{m}^{2}$ and grains/spike were not influenced by foliar treatments, only the higher 1000-grain weight contributed to higher yield in response to foliar treatments. One spray at different stages $\left(S_{2}\right.$ and $\left.S_{3}\right)$ gave similar higher yield over control and two sprays $\left(\mathrm{S}_{4}\right)$ gave the best result. Tilt application also gave positive yield response that was prominent in Kanchan compared to Shatabdi and Prodip. Severe leaf blight was found in Kanchan, which was effectively controlled by the foliar application of Tilt, thus $\mathrm{S}_{5}$ produced higher yield in Kanchan. This yield advantage was also attributed solely from higher 1000-grain weight as other yield component was statistically similar for different foliar treatments. Due to the interaction effect, the highest grain yield was obtained from $\mathrm{V}_{2} \mathrm{~S}_{4}$ and $\mathrm{V}_{3} \mathrm{~S}_{4}$ which indicated that Shatabdi and Prodip were very much responsive to foliar spray of potassium orthophosphate. Also the treatment combinations of $\mathrm{V}_{2} \mathrm{~S}_{4}$ and $\mathrm{V}_{3} \mathrm{~S}_{4}$ gave the highest 1000-grain weight indicating that grain size of Prodip and Shatabdi was improved in response to foliar application of potassium orthophosphate. The result indicated that two sprays of potassium orthophosphate solution (0.1\%) at 70 and 80 DAS was effective in improving grain yield of Prodip and Shatabdi by influencing leaf SPAD value, leaf area, and 1000-grain weight.

\section{Kernel quality}

Kernel quality of wheat measured as kernel size distribution, notched bally kernel and black pointed kernel were significantly influenced by foliar treatments (Fig. 4). The percentage of bold grain (1000-grain weight $>45 \mathrm{~g}$ ) was the highest in variety Prodip $(61 \%)$, and however, this was statistically similar to the variety Kanchan and Shatabdi. The $\mathrm{S}_{4}$ foliar treatment resulted in the maximum bold grain production that was statistically similar to $S_{2}$, but higher than other treatments. The percentage of small, immature, and notched bally kernel also varied due to foliar application of osmotic solute. Smaller grains were minimum in $S_{4}$ and maximum in $S_{1}$. The number of immature kernel significantly decreased due to two sprays of potassium orthophosphate $\left(S_{4}\right)$. Other foliar treatments viz., $S_{2}$ and $S_{3}$ were also effective in reducing the numbers of immature grains compared to control. Foliar application of osmotic solute improved green area duration that contributed to photosynthesis and reduced the force maturation and thereby resulted in formation of bolder grains. Therefore, osmotic solute resulted in decreased proportion of smaller and immature grains 
by increasing the production of bold grains. Formation of notched bally kernel is considered as an indicator of plant exposure to abiotic stress and forced maturation. The number of notched bally kernel was considerably reduced by two foliar applications of osmotic solute, whereas the number of black point kernel was nearly similar for different treatments with an exception in $\mathrm{S}_{5}$. The foliar treatment $S_{5}$ resulted in the least number of black point kernel. The result demonstrated that foliar application of potassium orthophosphate was effective in improving kernel quality by increasing grain size and Tilt application that had positive role in improving seed quality by reducing black point kernel.

\section{Conclusion}

The wheat varieties Prodip and Shatabdi were responsive to foliar application of potassium orthophosphate. Two sprays of potassium orthophosphate at 70 and 80 DAS produced the maximum grain yield. The yield advantage was due to increased 1000-grain weight induced by longer green area duration and higher leaf chlorophyll content in response to foliar treatments. This experiment introduces osmotic solute as a technique of increasing crop tolerance to higher temperature and this can be adapted at farm level to improve wheat yield under terminal heat stress.

\section{References}

Ahmed, S. M. and C. A. Meisner. 1996. Wheat Research and Development in Bangladesh. Bangladesh - Australia Wheat Improvement Project and CIMMYT Bangladesh, Dkaka. Pp. 201.

Benbella, M. and G. M. Paulsen. 1998. Efficacy of treatment for delaying senescence of wheat leaves. II. Senescence and grain yield under field conditions. Agron. J. 90: 332-338.

Fisher, R. A., D. Rees, K. D. Sayre, Z. M. Lu, A. G. Condon, and A. L. Savedra. 1998. Wheat yield progress associated with higher stomatal conductance and photosynthetic rate, and cooler canopies. Crop Sci. 38: 1467-1475.

Gibson, R. L. and G. M. Paulsen. 1999. Yield component of wheat grown under high temperature stress during reproductive growth. Crop Sci. 39: 1841-1846.

Hong-Bo S., C. Xiao-Yan, C. Li-Ye, Z. Xi-Ning, W. Gangh, Y. Yong-Bing, Z. ChangXing, Z. Zan-Min. 2006: Investigation on the relationship of proline with wheat antidrought under soil water deficits. Colloids Surf. B. Biointerfaces 53: 113-119.

Iftikhar, S., S. Azad and A. Munir. 2010. Incidence of Bipolaris Sorokiniana in Punjab and Khyber Pakhtoon, Pakistan. Pak J. Phytopathol. 22(1): 95-97.

Rahman, M. A,, C. A. Meisner, J. M. Duxbury, J. G. Lauren and A. B. S. Hossain. 2001. Yield response and change in nutrient availability by application of lime, fertilizer, 
and micronutrients in acidic soil within a rice-wheat cropping system. Bangladesh $J$. Agric. Res. 26(3): 357-365.

Rahman, M. A., J. Chikushi, S. Yoshida, H. Yahata, and E. Yasunsga. 2005. Effect of high air temperature on grain growth and yields of wheat genotypes differing in heat tolerance. J. Agric. Meteorology 60(5): 605-608.

Rahman, M. A., J. Chikushi, S. Yoshida, and A. J. M S. Karim. 2009. Growth and yield components of wheat genotypes exposed to temperature stress under control environment. Bangladesh J. Agric. Res. 34(3): 361-372.

Stone , P. J. and M. E. Nicolas. 1998. The effect of duration of heat stress during grain filling on two wheat varieties differing in heat tolerance: Grain growth and fractional protein accumulation. Aust. J. Plant Physiol. 25: 13-20. 